Original Paper http://ajol.info/index.php/ijbcs http://indexmedicus.afro.who.int

\title{
Syntheses, characterizations and antioxidant activities of copper complexes of quercetin as influenced by redox states
}

\author{
Luqmon AZEEZ $^{1 *}$, Abdulrasaq O. OYEDEJI ${ }^{2}$, Sulaimon O. ADEWUYI ${ }^{3}$ and \\ Kazeem O. TIJANI ${ }^{4}$ \\ ${ }^{1}$ Environmental, Analytical and Nutritional Chemistry Research Laboratory, \\ Department of Pure and Applied Chemistry, Osun State University, Osogbo, Nigeria. \\ ${ }^{2}$ Department of Science Laboratory Technology, The Federal Polytechnic, Ilaro, Nigeria. \\ ${ }^{3}$ Department of Pure and Applied Chemistry, Ladoke Akintola University of Technology, Nigeria. \\ ${ }^{4}$ Industrial and Environmental Chemistry Unit, Department of Chemical Sciences, \\ Fountain University, Osogbo, Nigeria. \\ *Corresponding author; E-mail: azeez012000@yahoo.com, Tel: +2348061538999
}

\begin{abstract}
Copper is an essential element for living but imbalance between $\mathrm{Cu}^{+}$and $\mathrm{Cu}^{2+}$ produces free radicals. Quercetin is an effective metal chelator and its chelates are often better free radical scavengers than free quercetin. In this study, the syntheses, characterizations, antioxidant activities of quercetin as well as its $\mathrm{Cu}$ (I) and $\mathrm{Cu}$ (II) complexes using UV-VIS, IR spectrometric methods, and 2,2-diphenyl-1-picrylhydrazyl (DPPH) scavenging assay were investigated. 1:1 and 2:1 stoichiometric ratios were obtained for the dark-brown $\mathrm{Cu}^{+}$ and green $\mathrm{Cu}^{2+}$ quercetin complexes respectively. Bathochromic shifts from $268 \mathrm{~nm}$ (band II) and $362 \mathrm{~nm}$ (band I) in quercetin were observed at $302 \mathrm{~nm}$ and $386 \mathrm{~nm}$ for $\mathrm{Cu}$ (I) -quercetin complex and at $281 \mathrm{~nm}$ and $394 \mathrm{~nm}$ for $\mathrm{Cu}$ (II) - quercetin complex. FT-IR showed shifts in the positions of carbonyl and hydroxyl groups with presence of bands at $932.01 \mathrm{~cm}^{-1}$ in $\mathrm{Cu}$ (I) - quercetin and $928.57 \mathrm{~cm}^{-1}$ in $\mathrm{Cu}$ (II) - quercetin confirming complexation. Both complexes were better free radical scavengers than free quercetin with $\mathrm{Cu}$ (I)-quercetin complex having the highest antioxidant activity. Higher antioxidant activity and differences in spectra characters of $\mathrm{Cu}(\mathrm{I})$-quercetin complex are related to relative stability of fully filled orbital of $\mathrm{Cu}^{+}$over $\mathrm{Cu}^{2+}$. (C) 2015 International Formulae Group. All rights reserved.
\end{abstract}

Keywords: Oxidation state, relative stability, DPPH, Stoichiometric ratio, complexation

\section{INTRODUCTION}

Copper $(\mathrm{Cu})$ is a transition element that occurs as $\mathrm{Cu}^{+}$(cuprous) and $\mathrm{Cu}^{2+}$ (cupric). $\mathrm{Cu}^{+}\left[3 \mathrm{~d}^{10}\right]$ is more stable than $\mathrm{Cu}^{2+}\left[3 \mathrm{~d}^{9}\right]$ because of stability of fully filled d-orbital (Olajire, 2005). $\mathrm{Cu}$ is a potent antimicrobial agent and is involved as a catalytic cofactor in hemoglobin formation, respiration, xenobiotic metabolism and antioxidant defense mechanism (Mercer, 2001; Puig and Thiele, 2002; Omoto et al., 2005). As essential as $\mathrm{Cu}$ is to living organisms, it is also toxic because its ions are potent generators of free radicals (Puig and Thiele, 2002; Panhwar et al., 2010; Riha et al., 2014). These properties are driven by its ability to cycle between two redox states; oxidized $\mathrm{Cu}^{2+}$ and reduced $\mathrm{Cu}^{+}$ (Mercer, 2001; Omoto et al., 2005; Aaseth et 
al., 2015). However, in the process of moving between $\mathrm{Cu}^{+}$and $\mathrm{Cu}^{2+}$ states, $\mathrm{Cu}$ imbalance is produced and leads to generation of free hydroxyl radicals which can damage lipids, proteins and DNA and disturb the synthesis of iron sulfur clusters (Festa and Thiele, 2011; Bukhari et al., 2008; Riha et al., 2014). Though each organism has in place mechanisms to safely excrete the excess $\mathrm{Cu}$ ions in its body, this could be hampered when excess ions are produced. Therefore, chelation therapy can be used to remove excess $\mathrm{Cu}$ ions from vulnerable sites in critical organs (Omoto et al., 2005; Aaseth et al., 2015).

Chelation therapy is a promising method in treating pathological diseases arising from oxidative stress caused by excess or dysregulation of transition metals. This is achieved by suppressing the metal induced toxicity (Dehghan and Khoshkam, 2012; Riha et al., 2014). Chelating agents such as flavonoids have natural ways of complexing toxic metals and are easily excreted from the body. This plays a major role in limiting metal bioavailability and suppressing metal toxicity (Malešev and Kunti, 2007; Riha et al., 2014).

Flavonoids are known to possess biological and pharmacological properties such as anti-cancer, anti-ulcer, anti-allergic, antioxidant, antiviral and anti-inflammatory needed in cardiovascular protection (Bukhari et al., 2008; Olajire and Azeez, 2011). They are present in fruits, vegetables and have free radical scavenging ability (Malešev and Kunti, 2007; Panhwar et al., 2010; Dehghan and Khoshkam, 2012). They are effective metal chelators and their chelating ability is widely believed as another mechanism of their antioxidant activity. These chelates have been reported to possess higher potency against free radicals than free flavonoids as it has confirmed that the biological activity of organic ligands such as flavonoids can be increased when co-coordinated with suitable metal ion thereby providing better protection against oxidative stress. Flavonoids chelate using carbonyl oxygen and hydroxyl groups present in their molecules (Kostyuk et al.,
2004; Moridani et al., 2003; Malešev and Kunti, 2007; Pereira et al., 2007; Bukhari et al., 2008; Dehghan and Khoshkam, 2012).

Quercetin (3, 3', 4', 5, 7 pentahydroxyflavone) is one of the most common flavonols (a class in flavonoids) found in tea, onions, nuts, berries, cauliflower, and cabbage and it reacts with free radicals by donating its proton without itself becoming a radical. It is a strong metal chelator and a potent antioxidant compound possessing higher antioxidant activity than $\alpha$-tocopherol, L-ascorbic acid and butylated hydroxylanisol (BHA) (Kostyuk et al., 2004; Moridani et al., 2003; Malešev and Kunti, 2007; Pereira et al., 2007; Olajire and Azeez, 2011; Dehghan and Khoshkam, 2012). It possesses three possible chelating sites in competition: the 3-hydroxy4-carbonyl, the 5-hydroxy-4-carbonyl, and the 3', 4'-dihydroxyl (catechol) groups. Studies on complexation of metals using quercetin have been reported for $\mathrm{Fe}^{2+}, \mathrm{Fe}^{3+}, \mathrm{Cu}^{2+}, \mathrm{Zn}^{2+}$ and were found to be more effective against radicals than free quercetin. These complexes have shown better efficiencies in protecting red blood cells against asbestos-induced oxidative injury in vitro (Kostyuk et al., 2004; Moridani et al., 2003).

Since $\mathrm{Cu}$ is easily converted from $\mathrm{Cu}^{2+}$ to $\mathrm{Cu}^{1+}$ with its attendant toxicity, little or no study has reported the possible effects this conversion can have on the antioxidant activities of their chelates, hence, this study aimed at determining the effects of redox states on syntheses, spectra characterizations and antioxidant activities of copper complexes of quercetin.

\section{MATERIALS AND METHODS \\ Chemicals}

2,2-diphenyl-1-picrylhydrazyl (DPPH), copper (II) sulphate pentahydrate $\left(\mathrm{CuSO}_{4} .5 \mathrm{H}_{2} \mathrm{O}\right)$, copper (I) oxide $\left(\mathrm{Cu}_{2} \mathrm{O}\right)$, methanol and ethanol. All reagents were analar grade and were bought from Sigma Aldrich, Germany. Deionized-distilled water was used all through the experiments. 


\section{Instrumentation}

UV-visible spectra of quercetin, $\mathrm{Cu}$ (I) - quercetin and $\mathrm{Cu}$ (II) - quercetin complexes were obtained using Jenway 6405 UV-Visible spectrophotometer and Infrared spectra were recorded using $\mathrm{KBr}$ pellets in the spectral range $4000-400 \mathrm{~cm}^{-1}$ on FT-IR Spectrophotometer (Model 500, Buck Scientific Inc.).

\section{Stoichiometric ratios of copper ions with quercetin}

Job's method of continual variation was used to determine the stoichiometric ratio between quercetin and the $\mathrm{Cu}$ ions. Equimolar concentration $\left(4 \times 10^{-4} \mathrm{M}\right)$ solutions of quercetin, $\mathrm{Cu}_{2} \mathrm{O}$ and $\mathrm{CuSO}_{4} .5 \mathrm{H}_{2} \mathrm{O}$ were prepared. $\mathrm{Cu}_{2} \mathrm{O}$ and quercetin were mixed in different ratios varying from 1:9 to $9: 1$ and the absorbance was measured at $427 \mathrm{~nm}$. The same procedure was used for $\mathrm{CuSO}_{4} .5 \mathrm{H}_{2} \mathrm{O}$ and quercetin.

\section{Synthesis}

$\mathrm{Cu}$ (I) and $\mathrm{Cu}$ (II) complexes of quercetin were prepared using a modified method of Bukhari et al. (2008). For $\mathrm{Cu}_{2} \mathrm{O}$, solid quercetin $\left(0.3 \mathrm{~g}, 1 \times 10^{-3} \mathrm{~mol}\right)$ was dissolved in $20 \mathrm{ml}$ methanol in a $50 \mathrm{ml}$ round bottom flask placed on electromagnetic stirrer, this solution was mixed thoroughly until the quercetin completely dissolved to form yellow-colored solution, solid $\mathrm{Cu}_{2} \mathrm{O}(0.143 \mathrm{~g}$, $\left.1 \times 10^{-3} \mathrm{~mol}\right)$ was added quickly; the color of the solution turned dark brown with continued stirring for $2 \mathrm{hr}$ at room temperature. After stirring, the solution was filtered and the filtrate was evaporated using rotary evaporator. A dark brown solid was obtained $(0.41 \mathrm{~g})$. Elemental analysis of the complex was $\mathrm{C}=37.43 \%, \mathrm{H}=2.93 \%$ with molecular formula $\mathrm{C}_{15} \mathrm{H}_{14} \mathrm{Cu}_{2} \mathrm{O}_{10}$ and molecular mass $481.36 \mathrm{~g}$.

For $\mathrm{CuSO}_{4} .5 \mathrm{H}_{2} \mathrm{O}$, solid quercetin $(0.3$ $\left.\mathrm{g}, 1 \times 10^{-3} \mathrm{~mol}\right)$ was dissolved in $20 \mathrm{ml}$ methanol in a $50 \mathrm{ml}$ round bottom flask placed on electromagnetic stirrer, this solution was mixed thoroughly until the quercetin completely dissolved to form yellow-colored solution, solid $\mathrm{CuSO}_{4} .5 \mathrm{H}_{2} \mathrm{O}\left(0.355 \mathrm{~g}, 2 \times 10^{-3}\right.$ mol) was added quickly; the color of the solution turned green with continued stirring for $2 \mathrm{hr}$ at room temperature. After stirring, solution was filtered and the filtrate was evaporated using rotary evaporator. Green solid $(0.524 \mathrm{~g})$ was obtained. Elemental analysis of the complex gave $\mathrm{C}=30.05 \%, \mathrm{H}=$ $4.15 \%$ with molecular formula $\mathrm{C}_{17} \mathrm{H}_{28} \mathrm{Cu}_{2} \mathrm{O}_{18} \mathrm{~S}$ and molecular mass $6799.55 \mathrm{~g}$.

\section{Determination of antiradical activity}

The method of Olajire and Azeez (2011) was used for the determination of antioxidant activity. $1 \%, 0.8 \%, 0.6 \%, 0.4 \%$ and $0.2 \%$ solutions of quercetin, $\mathrm{Cu}$ (I) quercetin and $\mathrm{Cu}$ (II) - quercetin complexes were prepared. $1 \mathrm{ml}$ of each concentration was measured into test tubes and $4 \mathrm{ml}$ of $0.004 \mathrm{M}$ DPPH was added to each tube in a dark room. The blank was prepared by measuring $1 \mathrm{ml}$ of methanol in test tube and $4 \mathrm{ml}$ of DPPH was added. Both blank and samples were allowed to stand for 30 minutes in dark room before reading at wavelength $517 \mathrm{~nm}$. Antioxidant activity was calculated using the equation below:

$\% \mathbf{A}_{(517)}=\left[\left(A_{\text {blank }}-A_{\text {sample }}\right) / A_{\text {blank }}\right] \times 100$.

\section{RESULTS}

Stoichiometric ratio and physical properties

Job's method of continual variation was used to determine the stoichiometric ratio as presented in Figure 1. Absorbance plots of $\mathrm{Cu}$ (I) - quercetin complex and $\mathrm{Cu}$ (II) quercetin complex against mole fractions of quercetin have maximum absorptions at 0.4 for $\mathrm{CuSO}_{4} .5 \mathrm{H}_{2} \mathrm{O}$ and at 0.52 for $\mathrm{Cu}_{2} \mathrm{O}$. These show a 2:1 stoichiometric ratio for $\mathrm{Cu}$ (II) quercetin and 1:1 stoichiometric ratio for $\mathrm{Cu}$ (I) - quercetin. Syntheses of the complexes were done using these ratios. $\mathrm{Cu}$ (I) quercetin and $\mathrm{Cu}$ (II) - quercetin complexes were dark brown and green solids respectively which were not soluble in water but soluble in ethanol and methanol. 


\section{UV-visible spectra characterization}

Figure 2 shows the characteristic peaks of free quercetin, $\mathrm{Cu}$ (I) - quercetin and $\mathrm{Cu}$ (II) - quercetin complexes. In free quercetin, maximum absorptions $\left(\lambda_{\max }\right)$ were observed at $268 \mathrm{~nm}$ and $362 \mathrm{~nm}$ while $\mathrm{Cu}$ (I) -quercetin and $\mathrm{Cu}$ (II) - quercetin complexes have maximum absorptions $\left(\lambda_{\max }\right)$ at $302 \mathrm{~nm}$ and $386 \mathrm{~nm} ; 281 \mathrm{~nm}$ and $394 \mathrm{~nm}$ respectively. In quercetin, band II with $268 \mathrm{~nm}$ is a characteristic $\left(\lambda_{\max }\right)$ absorption attributable to transition from $\pi-\pi^{*}$ in the ring A consisting benzene ring while band I with $362 \mathrm{~nm}$ is characteristic $\lambda_{\max }$ of transition in the ring $\mathrm{B}$ consisting the cinnamoyl system and ranges from $300-400 \mathrm{~nm}$. Shifts in $\lambda_{\max }$ from 268 $\mathrm{nm}$ in quercetin (band II) to $302 \mathrm{~nm}$ and 281 $\mathrm{nm}$ in $\mathrm{Cu}$ (I) - quercetin and $\mathrm{Cu}$ (II) quercetin complexes respectively were obtained. Also, Shifts in $\lambda_{\max }$ from $362 \mathrm{~nm}$ (band I) in free quercetin to $386 \mathrm{~nm}$ and 394 $\mathrm{nm}$ in $\mathrm{Cu}$ (I) - quercetin and $\mathrm{Cu}$ (II) quercetin complexes respectively were observed.

\section{Infra-Red spectra characterization}

The coordination sites and binding properties in free quercetin, $\mathrm{Cu}(\mathrm{I})$ - quercetin and $\mathrm{Cu}$ (II) - quercetin complexes are presented in Table 1 . The stretching vibration of $\mathrm{C}=\mathrm{O}$ in free quercetin occurred at 1705.09 $\mathrm{cm}^{-1}$ which was shifted to $1718.33 \mathrm{~cm}^{-1}$ and $1727.97 \mathrm{~cm}^{-1}$ in $\mathrm{Cu}$ (I) - quercetin and $\mathrm{Cu}$ (II) quercetin complexes respectively. The shift in $\mathrm{O}-\mathrm{H}$ was from $3418.37 \mathrm{~cm}^{-1}$ in free quercetin to $3425.60 \mathrm{~cm}^{-1}$ and $3453.53 \mathrm{~cm}^{-1}$ in $\mathrm{Cu}$ (I) quercetin and $\mathrm{Cu}$ (II) - quercetin complexes respectively. The bands at $1388.91 \mathrm{~cm}^{-1}$, $1614.62 \mathrm{~cm}^{-1}$ and $1226.57 \mathrm{~cm}^{-1}$ were related to $v(\mathrm{C}-\mathrm{OH}), v(\mathrm{C}=\mathrm{C})$ and $v(\mathrm{C}-\mathrm{O}-\mathrm{C})$ in free quercetin which were shifted to $1373.56 \mathrm{~cm}^{-1}$, $1612.31 \mathrm{~cm}^{-1}$ and $1266.72 \mathrm{~cm}^{-1}$ in $\mathrm{Cu}$ (I) quercetin complex and, $1363.18 \mathrm{~cm}^{-1}, 1616.73$ $\mathrm{cm}^{-1}$ and $1261.59 \mathrm{~cm}^{-1}$ in and $\mathrm{Cu}$ (II) quercetin complex. The presence of $v(\mathrm{Cu}-\mathrm{O})$ at $932.01 \mathrm{~cm}^{-1}$ and $928.57 \mathrm{~cm}^{-1}$ in $\mathrm{Cu}$ (I) quercetin and $\mathrm{Cu}$ (II) - quercetin complexes respectively was obtained.

\section{Antioxidant activity}

Figure 3 shows the antioxidant activities of free quercetin, $\mathrm{Cu}$ (I) - quercetin and $\mathrm{Cu}$ (II) - quercetin complexes. $\mathrm{Cu}$ (I) quercetin complex had highest antioxidant activity $(86.9 \%)$ followed by quercetin (76.4\%) and $\mathrm{Cu}$ (II) - quercetin complex (73.9\%). Inhibitory concentration at which $50 \%$ of the radicals were scavenged $\left(\mathrm{IC}_{50}\right)$ of quercetin, $\mathrm{Cu}$ (I) - quercetin and $\mathrm{Cu}$ (II) quercetin complexes are $0.52 \mathrm{mg} / \mathrm{ml}, 0.39$ $\mathrm{mg} / \mathrm{ml}, 0.56 \mathrm{mg} / \mathrm{ml}$ respectively.

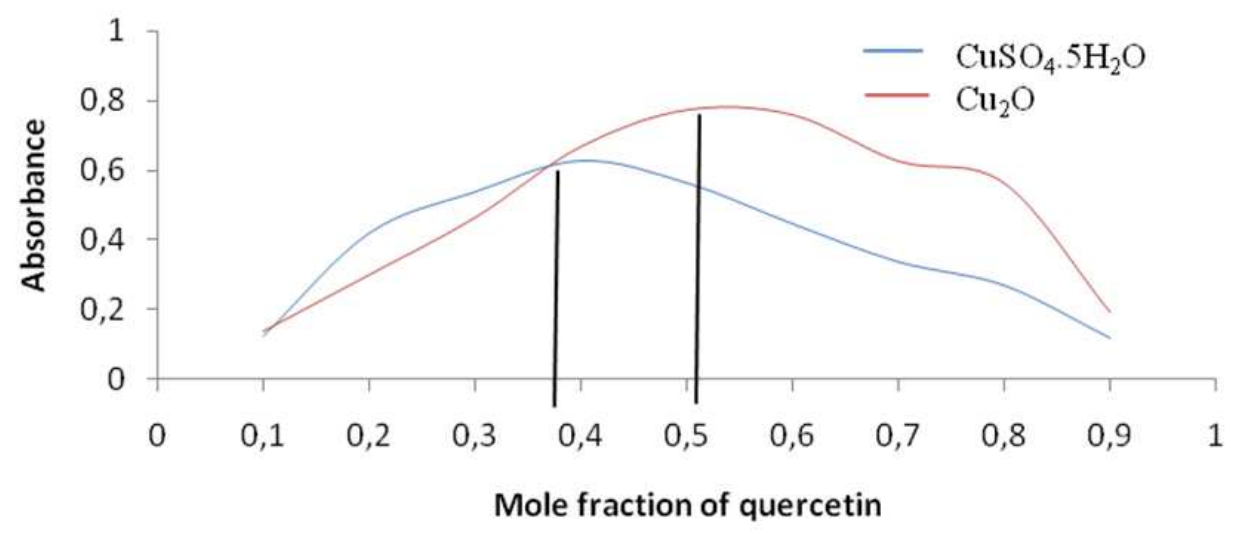

Figure 1: Absorbance plots of $\mathrm{CuSO}_{4} \cdot 5 \mathrm{H}_{2} \mathrm{O}$ and $\mathrm{Cu}_{2} \mathrm{O}$ against mole fractions of quercetin. 


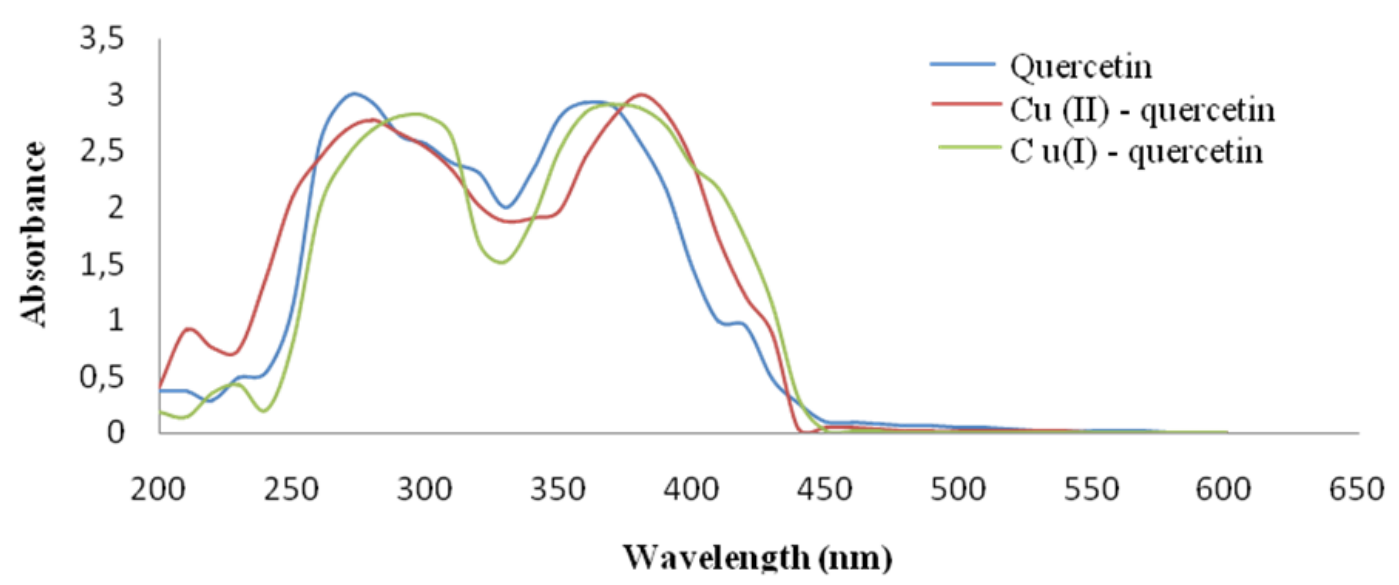

Figure 2: UV-Visible spectra of free quercetin $\mathrm{Cu}$ (I) - quercetin and $\mathrm{Cu}$ (II) - quercetin complexes.

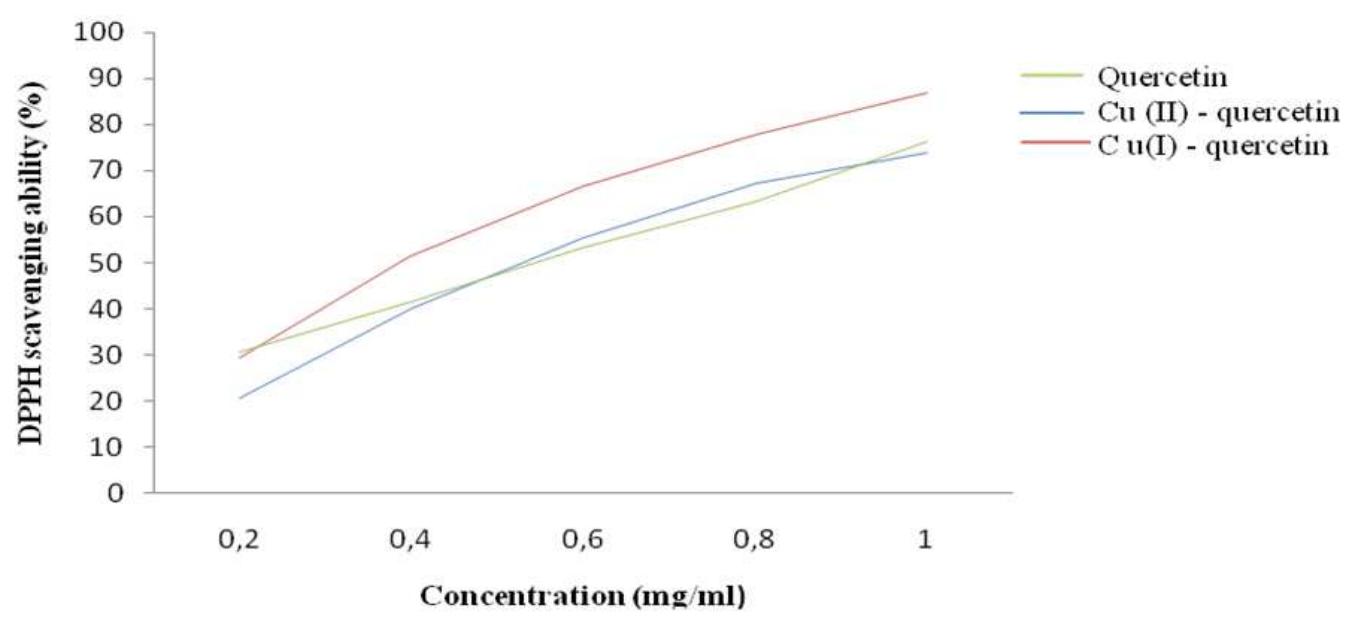

Figure 3: Antioxidant activities of quercetin, $\mathrm{Cu}$ (I) - quercetin and $\mathrm{Cu}$ (II) - quercetin complexes.

Table 1: FT-IR bands $\left(\mathrm{cm}^{-1}\right)$ of quercetin, $\mathrm{Cu}$ (I) - quercetin and $\mathrm{Cu}$ (II) - quercetin complexes.

\begin{tabular}{lccc}
\hline Bands & Quercetin & Cu (I) - quercetin & Cu (II) - quercetin \\
\hline$v(\mathrm{O}-\mathrm{H})$ & $3418.37 \mathrm{~s}$ & $3425.60 \mathrm{~s}$ & $3453.53 \mathrm{~s}$ \\
$v(\mathrm{C}=\mathrm{O})$ & $1705.09 \mathrm{~s}$ & $1718.33 \mathrm{~s}$ & $1727.97 \mathrm{~s}$ \\
$\mathrm{v}(\mathrm{C}-\mathrm{H})$ & $2931.31 \mathrm{~s}$ & $2936.31 \mathrm{~s}$ & $2996.84 \mathrm{~s}$ \\
$\mathrm{v}(\mathrm{C}-\mathrm{OH})$ & $1388.91 \mathrm{~m}$ & $1373.56 \mathrm{~m}$ & $1363.18 \mathrm{~m}$ \\
$\mathrm{v}(\mathrm{C}-\mathrm{O})$ & $1107.18 \mathrm{~s}$ & $1112.22 \mathrm{~s}$ & $1164.58 \mathrm{~s}$ \\
$\mathrm{v}(\mathrm{C}=\mathrm{C})$ & 1614.62 & $1612.31 \mathrm{~s}$ & 1616.73 \\
$\mathrm{v}(\mathrm{C}-\mathrm{O}-\mathrm{C})$ & $1226.57 \mathrm{~s}$ & $1266.72 \mathrm{~m}$ & $1261.59 \mathrm{~s}$ \\
$\mathrm{v}(\mathrm{Cu}-\mathrm{O})$ & & $932.01 \mathrm{~s}$ & 928.57 \\
\hline \multicolumn{2}{c}{$\mathrm{s}-$ Strong and $\mathrm{m}-$ Medium. } & &
\end{tabular}




\section{DISCUSSION}

Metal-flavonoid complexes are of high importance and are therefore characterized using different spectroscopic methods to understand their physical properties. $\mathrm{Cu}$ (I) quercetin and $\mathrm{Cu}$ (II) - quercetin complexes in this study were dark-brown and green colored respectively. This is supported by the evidence that metal-flavonoid complexes are often colored (Malešev and Kunti, 2007).

Formation of complexes was confirmed using UV-Vis and IR spectroscopic methods. Bathochromic shifts obtained in UV-Vis absorption bands of copper complexes in comparison with quercetin could have been caused by increased conjugative effects of $\mathrm{Cu}$ (I) and $\mathrm{Cu}$ (II) suggesting interactions between these metals and condensed rings of the flavonoids. It has been reported that bathochromic shifts are usually observed in the absorption bands of flavonoid in the presence of metal ions (Malešev and Kunti, 2007). This is in agreement with results reported by Bukhari et al. (2008) and Panwar et al. (2010) that indicate that these shifts are caused by the binding of the metal ion with flavonoid.

Also, shifts in $v(\mathrm{OH})$, and $v(\mathrm{CO})$ positions of quercetin and presence of $v(\mathrm{Cu}-$ $\mathrm{O}$ ) which was absent in free quercetin indicate that the complexes were formed, and hydroxyl and carbonyl groups were involved in the complexation. It has been reported that hydroxyl and carbonyl groups at 3 and 4 positions are the first sites of chelation for flavonoid especially for flavonols while hydroxyl groups at 3' and 4' bind the second metal (Malešev and Kunti, 2007; Bukhari et al., 2008; Panhwar et al., 2010; Dehghan and Khoshkam, 2012). Therefore, in this study hydroxyl groups at 3, 3', 4'- positions and carbonyl group at 4 - positions were identified as the binding sites for $\mathrm{Cu}$ (II) - quercetin complex because it is 2:1 while 3-hydroxyl and 4-carbonyl positions were identified as the binding sites for $\mathrm{Cu}$ (I) - quercetin complex because it is $1: 1$.
Metal-flavonoid complexes have been reported to possess higher antioxidant against free radicals than free flavonoid. In this study, $\mathrm{IC}_{50}$ of the complexes showed that they possess higher scavenging ability against free radicals than free quercetin with $\mathrm{Cu}$ (I) quercetin the most potent because the lower the $\mathrm{IC}_{50}$ the more potent the complex is (Olajire and Azeez, 2011). These results are in agreement with Kostyuk et al. (2004) who reported that flavonoid complexes are more potent free flavonoid in scavenging free radicals. Equally, increase in the antioxidative potencies of $\mathrm{Cu}$ (I) - quercetin and $\mathrm{Cu}$ (II) quercetin complexes suggests that $\mathrm{Cu}$ (I) and $\mathrm{Cu}$ (II) have significantly modified the chemical composition of the quercetin (Panhwar et al., 2010). The reason could be due to the decrease in oxidation potential of quercetin by $\mathrm{Cu}$ (I) and $\mathrm{Cu}$ (II) complexation thus, making it readily oxidized, more reactive and effective than free quercetin (Bukhari et al., 2008; Panhwar et al., 2010).

\section{Conclusion}

This study has reported the effects of redox states on syntheses, spectra characterizations, antioxidant activities of quercetin and its copper complexes. The complexes and quercetin exhibited different spectroscopic properties while complexes possessed better free radical scavenging ability than free quercetin with $\mathrm{Cu}$ (I)quercetin complex having the highest antioxidant activity.

\section{COMPETING INTEREST}

Authors have not declared any conflict of interest.

\section{REFERENCES}

Aaseth J, Skaug MA, Cao Y, Andersen O. 2015. Chelation in metal intoxication principles and paradigm. J. Trace Elem. Med. Biol., 31: 260 - 266. DOI:10.1016/j.jtemb.2014.10.001.

Bukhari SB, Memona S, Tahir MM, Bhanger MI. 2008. Synthesis, characterization 
and investigation of antioxidant activity of cobalt-quercetin complex. J. Mol. Struc., 892:39 - 46. DOI: 10.1016/j.molstruc.2008.04.050.

Dehghan G, Khoshkam Z. 2012. Tin(II)quercetin complex: Synthesis, spectral characterization and antioxidant activity. Food Chem., 131: 422-426. DOI:10.1016/j.foodchem.2011.08.074.

Festa RA, Thiele DJ. 2011. Copper: An essential metal in biology. Current Biol., 21(21): R877-R883. DOI: 10.1016/j.cub.2011.09.040.

Kostyuk VA, Potapovich AI, Vladykovskaya EN, Korkina LG, Afanas'ev IB. 2004. Experimental evidence that flavonoid metal complexes may act as mimics of superoxide dismutase. $A B B, \mathbf{3 8 5}$ : 129-137. DOI: $10.1016 /$ j.abb.2004. 06.008 .

Malešev D, Kunti V. 2007. Investigation of metal-flavonoid chelates and the determination of flavonoids via metalflavonoid complexing reactions. J. Serb. Chem. Soc., 72 (10): 921 - 939. DOI: 10.2298/JSC0710921M.

Mercer JB. 2001. The molecular basis of copper-transport diseases. Trends Mol.

Med., 7(2): 64-69. DOI: 10.1016/S1471-4914(01)01920-7.

Moridani MY, Pourahmad J, Bui H, Siraki A, O'Brien PJ. 2003. Dietary flavonoid iron complexes as cytoprotective superoxide radical scavengers. Free Rad. Biol. Med., 34: 243-253. DOI: 10.1016/S0891-5849(02)01241-8.

Olajire AA. 2005. Fundamental University Organic and Inorganic Chemistry $\left(2^{\text {nd }}\right.$ edn). Sina 2tees Publications: Ogbomoso, Nigeria.

Olajire AA, Azeez L. 2011. Total antioxidant activity, phenolic, flavonoid and ascorbic acid contents of Nigerian Vegetables. Afr. J. Food Sci. Tech., 2(2): 022-029.

Omoto A, Kawahito Y, Prudovsky I, Tubouchi Y, Kimura M, Ishino H, Wada M, Yoshidan M, Kohno M, Yoshimura R. 2005. Copper chelation with tetrathiomolybdate suppresses djuvantinduced arthritis and inflammationassociated cachexia in rats. Arthritis Res. Ther., 7(6): R1174-R1182. DOI: 10.1186/ar1801

Panhwar QK, Memon S, Bhanger MI. 2010. Synthesis, characterization, spectroscopic and antioxidation studies of $\mathrm{Cu}$ (II)-morin complex. J. Mol. Struc., 967: $47-\quad 53 . \quad$ DOI: 10.1016/j.molstruc.2009.12.037

Pereira RMS, Andrades NED, Paulino N, Sawaya ACHF, Eberlin MN, Marcucci MC, Favero GM, Novak EM, Bydlowski SP. 2007. Synthesis and Characterization of a metal complex containing naringin and $\mathrm{Cu}$, and its antioxidant, antimicrobial, anti-inflammatory and tumor cell cytotoxicity. Molecules, 12: $1352-1366$.

Puig S, Thiele DJ. 2002. Molecular mechanism of copper uptake and distribution. Curr Opin Chem. Biol., 6: 171-180. DOI: 10.1016/S13675931(02)00298-3

Rıha,M, Karlickov J, Filipsky T, Macakov K, Rocha L, Bovicelli P, Silvestri P, Saso L, Jahodar L, Hrdina R, Mladenka P. 2014. In vitro evaluation of copperchelating properties of flavonoids. RSC Advances, 4: 32628-32638. DOI: $10.1039 / \mathrm{c} 4 \mathrm{ra0} 4575 \mathrm{k}$ 